\title{
The effect of first- and third-generation prophylactic antibiotics on hospitalization and medical expenditures for cardiac surgery
}

Sung-Jin Bae ${ }^{1,2+}$, Inah Kim ${ }^{1,3^{*}+}$, Jaechul Song ${ }^{1,3}$ and Euy-Suk Chung ${ }^{2}$

\begin{abstract}
Background: This study investigated the efficacy of first-generation (cefazolin) and third-generation (ceftizoxime) prophylactic antibiotics in patients undergoing cardiac surgery and the incidence of surgical site infections, hospitalizations, and medical costs.

Methods: All adult patients ( $\geq 20$ years) undergoing cardiac surgery at one hospital from January 01, 2009, to December 31, 2016, were included in this study. A single prophylactic antibiotic was administered at a dose of $1 \mathrm{~g}$ within one hour of the surgical incision and for three days after surgery at eight-hour intervals. After propensity score matching, 194 patients in each antibiotic prophylaxis group (first-generation vs third-generation) were analyzed. Among the 388 patients, the incidence of surgical site infections was compared according to the type of prophylactic antibiotic, and risk factors were evaluated by chi-squared tests followed by multivariate logistic regression analysis.

Results: The incidence of deep surgical site infections was significantly lower in the first-generation group (5.7\%) than in the third-generation group (16.5\%). The pathogens isolated from the surgical infection sites were similarly distributed in both groups. However, the prevalence of highly infectious gram-positive bacteria was more than that of gram-negative bacteria (67\% vs 23\%). The preoperative hospitalization duration, mean operation time, and ventilator use time were similar in both groups, but the postoperative hospitalization duration was significantly shorter in the first-generation group (25.5 days) than in the third-generation group (29.8 days). In addition, the medical costs were lower in the first-generation group (20,594 USD) than in the third-generation group (26,488 USD).
\end{abstract}

Conclusion: In conclusion, the first-generation prophylactic antibiotic was better than the third-generation in reducing surgical site infection rates, hospitalization length, and medical expenditures.

Keywords: Prophylactic antibiotics, Surgical site infection, Propensity score matching, Medical expenditures

\section{Background}

In a placebo-controlled trial, the placebo group showed an increased incidence of surgical site infections by $20-50 \%$, confirming the appropriateness of using prophylactic antibiotics in cardiac surgery [1-3]. Surgical

\footnotetext{
*Correspondence: inahkim@hanyang.ac.kr

${ }^{\dagger}$ Sung-Jin Bae and Inah Kim contributed equally to this work

${ }^{1}$ Department of Health Science, Hanyang University Graduate School, Seoul, Korea

Full list of author information is available at the end of the article
}

site infections (SSIs) are common hospital infections that increase the morbidity and mortality of patients, treatment duration, and socioeconomic costs. According to the National Centers for Disease Control and Prevention (CDC) and the National Nosocomial Infections Surveillance (NNIS) report, surgical site infections account for $14-16 \%$ of hospital-associated infections in hospitalized patients [4]. SSIs increase the average number of days of hospitalization by 6.5 days, with additional hospitalization costs of $\$ 18,900$, while the costs associated with patient mortality is $\$ 60,547$ more than patient survival

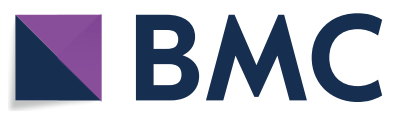

(c) The Author(s) 2022. Open Access This article is licensed under a Creative Commons Attribution 4.0 International License, which permits use, sharing, adaptation, distribution and reproduction in any medium or format, as long as you give appropriate credit to the original author(s) and the source, provide a link to the Creative Commons licence, and indicate if changes were made. The images or other third party material in this article are included in the article's Creative Commons licence, unless indicated otherwise in a credit line to the material. If material is not included in the article's Creative Commons licence and your intended use is not permitted by statutory regulation or exceeds the permitted use, you will need to obtain permission directly from the copyright holder. To view a copy of this licence, visit http://creativecommons.org/licenses/by/4.0/. The Creative Commons Public Domain Dedication waiver (http://creativeco mmons.org/publicdomain/zero/1.0/) applies to the data made available in this article, unless otherwise stated in a credit line to the data. 
[5]. Korean studies showed that the length of hospitalization due to SSIs increased by 5.2 days, with an additional cost of more than $\$ 1800$ per incident [6]. Therefore, SSIs lead to mental, physical, and economic losses to patients, worsens the quality of life, wastes healthcare resources, and increases the financial burden on medical institutions.

The results of the 2006 Survey on Antibiotic Usage from the National Health Insurance Review and Assessment Service (HIRA) showed that the use of prophylactic antibiotics in Korean surgeries differed from the Guideline for Guidance and has been classified as an abuse of antibiotics $[7,8]$. The choice of prophylactic antibiotics is less appropriate for methicillin-resistant Staphylococcus sp. and can be covered by gram-positive bacteria and provides safe and cost-effective treatment but fails to reflect the domestic medical environment because it refers to guidelines from foreign clinical studies. In recent studies, sufficient medical institutions and research subjects were not available, which limited the generalizability of research results $[9,10]$. Since the start of the national hospital evaluation program (NHEP) in 2008 , the evaluation of prophylactic antibiotics for surgery was implemented as a comprehensive measure of antibiotic resistance management. In this evaluation program, unfavorable antibiotic choices were defined as the overuse of third-generation cephalosporin, aminoglycoside, combination of $\beta$-lactam with aminoglycoside, combination of vancomycin and other antibiotics. Procedures performed since 2008 were included in the NHEP assessment and the clinical performance results were officially reported to the public as well as to each hospital.

Third-generation prophylactic antibiotic, which was used from 2009 to 2012, was changed to first-generation prophylactic antibiotics due to the evaluation of prophylactic antibiotic use. The use of prophylactic antibiotics has been evaluated since 2012 to promote the prevention of SSIs. The benefit of university hospital institution in changing prophylactic antibiotics has not been identified. Therefore, we performed a comparative study of cephalosporin first-generation (cefazolin) and third-generation (ceftizoxime) antibiotics. The purpose of this study was to investigate the use of prophylactic antibiotics and the prevention of SSIs by analyzing the relationships between the use of prophylactic antibiotics and SSI rates.

\section{Materials and methods}

\section{Study population}

This study was a retrospective review of the electronic medical records of all patients who underwent cardiac surgery from January 01, 2009, to December 31, 2016, at a single university hospital. All patients had undergone full median sternotomy and cardiopulmonary bypass
(CPB). The inclusion criteria were coronary artery bypass grafting (CABG) and valve surgery. Patients with current active infections; those for whom antibiotics had been administered within two weeks of surgery; immunotherapy patients; patients with congenital heart disease, cardiac assistive devices, or extracorporeal membrane oxygenation (ECMO); and patients who had undergone aortic dissection or thoracotomy surgeries were excluded from the study. Of the 554 patients who underwent cardiac surgery, 243 received third-generation antibiotics (ceftizoxime) and 311 received first-generation antibiotics (cefazolin). According to the exclusion criterion, 27 patients in the third-generation group and 45 patients in the first-generation group were excluded. The final study included 216 patients in the third-generation group and 266 in the first-generation group. Following propensity score matching (PSM), a total of 194 patients were categorized into two groups (Fig. 1). The cephalosporinbased prophylactic antibiotics used were cefazolin (first-generation) and ceftizoxime (third-generation).

\section{Antibiotic regimen and surgical preparation}

A single cephalosporin antibiotic was administered. At least $1 \mathrm{~g}$ was administered intravenously over 15 to $20 \mathrm{~min}$, within one hour before the skin incision was made at the sternum, and additional doses were administered at eight-hour intervals for three days postoperatively. Because the timing of prophylactic antibiotic administration is important in preventing SSIs, we defined the antibiotic drug regimen as optimal prophylaxis if the antibiotic was administered within one hour before the first surgical incision. All preoperative procedures were conducted in the same way. The patients were given a chlorhexidine shower before surgery to reduce bacterial proliferation and prevent infection. In the operating room, on the day of surgery, all operative sites were painted with $3 \mathrm{M}$ DuraPrep surgical solution $(0.7 \%$ iodine-povacrylex, $3 \mathrm{M}$ Health) again. All operations were performed by two experienced cardiac surgeons. The surgical procedures have not been changed to date.

\section{Surgical site infections}

The sternal incision sites were evaluated daily by cardiac surgeons and four times a week by an infection management nurse. The diagnosis of identified SSIs was based on positive cultures, dehiscence of the sternotomy, high fever, local pain, redness, purulent drainage, and sternal instability. The duration of the SSI assessments was within 30 days from the beginning of the follow-up period to the end of follow-up based on the SSI guidelines from the CDC [11]. Nosocomial SSIs were defined according to the CDC criteria and mediastinitis was defined according to the Society of Thoracic Surgeons 


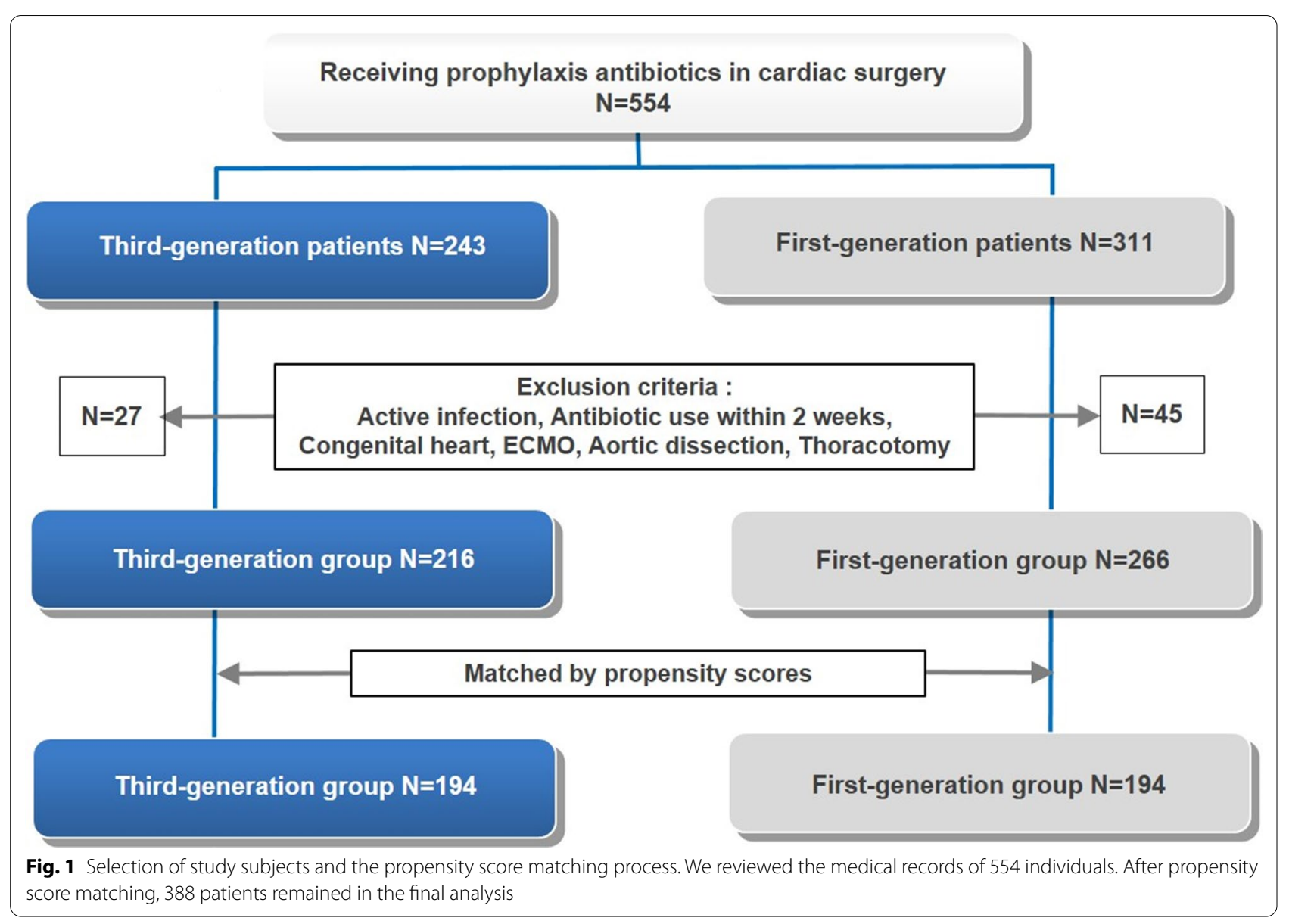

(STS) criteria [12, 13]. Wound cultures were obtained and clinically processed in the microbiology laboratory according to standard procedures.

\section{Costs}

The total hospital charges included all medical costs covered by health insurance, self-pay, optional care, and other medical costs. To investigate the costs related to SSIs, the pre-cardiac surgery examination costs, imaging costs, nursing costs, surgical costs, material costs, and admission fees were excluded from the total medical cost. All admission fees were reimbursed based on the admission fee for a six-person room. The hospital charges included post-cardiac surgery medication and treatment costs, examination fees, radiology fees, and treatment material costs for the management of early postoperative complications that occurred during hospitalization.

The daily weighted average costs for prophylactic antibiotics were 5.16 US dollars (USD)-5.20 US dollars (USD) for third-generation (ceftizoxime) and 1.08 USD1.24 USD for first-generation (cefazolin) antibiotics. The exchange rate was based on the rate for November 20, $2019(1 \mathrm{USD}=1175$ Korean won $\{\mathrm{KRW}\})$.

\section{Statistical analysis}

The continuous variables and categorical variables were analyzed by t-tests and chi-squared tests. PSM was used to control selection bias in group selection. This matching method is designed to compare the individual characteristics of two groups based on propensity scores and conditional probabilities. The first-generation and thirdgeneration groups were matched at a 1:1 ratio using the Greedy matching method [14]. Greedy matching is a method of setting a range of constant propensity scores around a treatment group using a caliper and selecting the closest objects in the control group corresponding to this range. The propensity scores used to estimate the probability of SSI incidence variables were calculated using logistic regression models. The covariates considered in calculating the propensity scores included age, sex, hypertension, obesity, diabetes, and smoking [15]. Differences in the baseline characteristics were evaluated by standardized differences in the matching variables. 
Standardized differences of $>10 \%$ usually represents a meaningful imbalance in the variables between the groups. The c-statistic and Hosmer-Lemeshow goodness-of-fit statistic were used to assess the propensity score model fit.

All outcome variables were compared between the propensity score-matched first-generation and thirdgeneration groups by $\mathrm{t}$-tests for numerical variables and chi-squared tests for categorical variables to determine the effect of SSI. The crude and adjusted odds ratios with 95\% confidence intervals (CI) were calculated to investigate the independent effect of prophylactic antibiotics on SSI parameters using logistic regression. Incremental cost-effectiveness ratios were calculated for significantly different variables between the two groups. All data analyses were performed using the statistical program SAS version 9.4 (SAS Institute Inc., Cary NC, USA).

\section{Ethics statement}

The present study protocol was reviewed and approved by the Institutional Review Board of Inje University Sanggye Paik Hospital (approval No. 2017-05-011-003). Informed consent was obtained from all patients before enrollment. Before the start of the study, the hospital research ethics review committee received the review. Related laws and regulations were followed throughout the research period.

\section{Results}

Among the 554 heart surgery procedures performed between January 2009 and December 2016, the general characteristics of 482 study subjects were compared before PSM and 388 patients after matching. Before matching, gender $(p=0.028)$, obesity $(p=0.024)$, hypertension $(p=0.042)$, and EuroSCORE risk assessment scores $(p<0.001)$ were significantly different between the two groups, but there were no statistically significant differences after PSM indicating that matching was balanced. The Hosmer-Lemeshow model goodness-of-fit test statistics were high (c-statistic $=0.63 ; 95 \%$ CI $0.54-$ 0.88) (Table 1).

In a comparison of sternal wound infection rates between the two groups, the incidence of superficial SSIs was $9.8 \%$ in the first-generation group and $10.3 \%$ in the third-generation group $(p=0.86)$. However, in deep SSIs rates in the first-generation antibiotic group (5.7\%) was significantly lower than that in the third-generation antibiotic group $(16.5 \%)(p<0.001)$. In multiple analysis, after adjusting for the variables of sex, age, diabetes, obesity, smoking, emergency, internal thoracic artery(ITA) use, ventilator, year and ICU stay, the incidence of deep SSIs was significantly lower in the first-generation than in the third-generation group (adjusted $\mathrm{OR}=1.25,95 \% \mathrm{CI}$ 1.07-1.91) (Table 2).

Gram positive bacteria were highly detected and the strain pattern in the both group. Pathogens isolated from the SSIs resulted in that a common infection with $\beta$-lactam-resistant gram-positive cocci (e.g., methicillinresistant $S$ aureus and methicillin-resistant Enterococci) were significantly less frequent in patients who received first-generation antibiotics (11 of 194 patients (5.6\%) than those who received third-generation antibiotics (24 of 194 patients $(12.4 \%), p<0.01)$. Also, methicillin-susceptible $S$. aureus and coagulase-negative Staphylococci were significantly less frequent in the first-generation group (9 of 194 patients $(4.4 \%)$ than in the third-generation group (25 of 194 patients (7.7\%), $p=0.028$ ) (see Additional file 1).

The preoperative hospitalization duration and ventilator use time were similar in the two groups at 8.4 \pm 8.6 days for the third-generation group and $7.8 \pm$ 7.6 days for the first-generation group $(p=0.262)$, and $1.2 \pm 2.2$ days for the third-generation and $1.2 \pm 2.1$ days for the first-generation $(p=0.679)$, respectively. However, a significant difference was found in the intensive care unit (ICU) stay duration, with $4.1 \pm 3.8$ days for the thirdgeneration group and $2.9 \pm 2.7$ days for the first-generation group $(p=0.008)$. The total hospitalization duration was increased significantly in the third-generation group to $29.8 \pm 18.7$ days compared to $25.5 \pm 20.1$ days in the first-generation group $(p=0.025)$ (Table 3$)$.

Compared to medical costs in the two groups, the total cost of daily medical expenses $(p<0.001)$ and the total hospitalization expenses $(p<0.001)$ were increased significantly in the third-generation group. The medical costs for non-infected patients were not statistically different $(p=0.092)$ between two groups but statistical differences for SSIs infected patients were observed in medical costs between the first and third-generation antibiotic groups $(p<0.05)$. The results showed that medical costs were reduced in the first-generation group, at 5894 USD (Table 4).

\section{Discussion}

The results of this study showed a significantly higher incidence of deep-SSIs and all-SSIs in the third-generation group. The first-generation antibiotic showed excellent antimicrobial effects on $\beta$-lactam-resistant gram-positive bacteria and remained stable for long-term at infection rates. In the comparison of hospitalization between the two groups, the preoperative hospitalization duration, mean operation time, and ventilator time were similar in both groups, but the hospitalization duration after surgery was significantly shorter in the first-generation antibiotic group. 
Table 1 General characteristics of study subjects receiving 3rd and 1st generation prophylactic antibiotics

\begin{tabular}{|c|c|c|c|c|c|c|c|c|}
\hline Variables & $\begin{array}{l}\text { 3rd } \\
\text { generation } \\
(n=216)\end{array}$ & $\begin{array}{l}\text { 1st } \\
\text { generation } \\
(n=266)\end{array}$ & $p$ value & SD (\%) & $\begin{array}{l}\text { 3rd } \\
\text { generation } \\
(n=194)\end{array}$ & $\begin{array}{l}1 \text { st } \\
\text { generation } \\
(n=194)\end{array}$ & $p$ value & SD (\%) \\
\hline \multicolumn{9}{|l|}{ Preoperative } \\
\hline \multicolumn{9}{|l|}{ Gender } \\
\hline Male & $130(60.2)$ & $186(69.9)$ & $0.028^{*}$ & -44.6 & $121(62.3)$ & $129(66.5)$ & 0.682 & -1.1 \\
\hline Female & $86(39.8)$ & $80(30.1)$ & & & $73(37.7)$ & $65(33.5)$ & & \\
\hline Age, years & $63.4 \pm 11.4$ & $64.2 \pm 11.9$ & 0.446 & -15.3 & $63.4 \pm 10.8$ & $63.6 \pm 12.8$ & 0.596 & -2.2 \\
\hline$<70$ years & $128(59.3)$ & $153(57.5)$ & 0.281 & 28.6 & $119(61.3)$ & $118(60.8)$ & 0.841 & 4.9 \\
\hline$\geq 70$ years & $88(40.7)$ & $113(42.5)$ & & & $75(38.7)$ & $76(39.1)$ & & \\
\hline \multicolumn{9}{|l|}{ Obesity } \\
\hline $\mathrm{BMI}<25$ & $158(73.1)$ & $184(69.2)$ & $0.024^{*}$ & 41.1 & $143(73.7)$ & $144(74.3)$ & 0.955 & -1.6 \\
\hline $\mathrm{BMI} \geq 25$ & $58(26.9)$ & $82(30.8)$ & & & $51(26.3)$ & $50(25.7)$ & & \\
\hline Smoker & $82(37.9)$ & $110(41.3)$ & 0.086 & -28.4 & $74(38.1)$ & $70(36.1)$ & 0.211 & 7.6 \\
\hline Hypertension & $149(69.1)$ & $204(76.7)$ & $0.042^{*}$ & -48.6 & $125(64.4)$ & $131(67.5)$ & 0.224 & -8.1 \\
\hline Diabetes mellitus (DM) & $61(28.2)$ & $90(33.8)$ & 0.112 & -13.4 & $53(27.3)$ & $52(26.8)$ & 0.918 & 0.7 \\
\hline Hypercholesterolemia & $24(11.1)$ & $34(12.8)$ & 0.441 & -10.2 & $20(10.3)$ & $19(9.8)$ & 0.868 & 0.7 \\
\hline Dialysis & $11(5.1)$ & $18(6.8)$ & 0.404 & -9.8 & $9(4.6)$ & $10(5.1)$ & 0.644 & -0.8 \\
\hline Chronic obstructive pulmonary disease & $14(6.5)$ & $21(7.9)$ & 0.702 & 0.8 & $13(6.7)$ & $14(7.2)$ & 0.851 & -0.9 \\
\hline Peripheral vascular disease & $13(6.0)$ & $22(4.7)$ & 0.343 & 12.0 & $9(4.6)$ & $14(7.2)$ & 0.186 & -7.2 \\
\hline \multicolumn{9}{|l|}{ LV dysfunction } \\
\hline$E F<30 \%$ poor & $22(10.2)$ & $25(9.4)$ & 0.481 & 2.9 & $19(9.8)$ & $21(10.8)$ & 0.657 & -3.7 \\
\hline EF $30-50 \%$ moderate & $56(25.9)$ & $80(30.1)$ & & & $51(26.3)$ & $59(30.4)$ & & \\
\hline$E F>50 \%$ & $138(63.9)$ & $161(60.1)$ & & & $124(63.9)$ & $114(58.8)$ & & \\
\hline \multicolumn{9}{|l|}{ EuroSCORE risk index } \\
\hline Category $1(\leq 2)$ & $112(51.8)$ & $137(51.5)$ & $<0.001$ & -51.5 & $101(51.9)$ & $100(51.5)$ & 0.388 & 10.6 \\
\hline Category 2 (3-5) & $56(26.0)$ & $102(38.4)$ & & & $51(26.2)$ & $72(37.1)$ & & \\
\hline Category $3(\geq 6$ ) & $48(22.2)$ & $27(10.1)$ & & & $42(21.9)$ & $22(11.4)$ & & \\
\hline \multicolumn{9}{|l|}{ Intraoperative } \\
\hline \multicolumn{9}{|l|}{ Surgical status } \\
\hline Elective & $185(85.7)$ & $237(89.1)$ & 0.110 & -7.6 & $172(88.7)$ & $174(89.7)$ & 0.249 & 9.3 \\
\hline Urgent & $24(11.1)$ & $19(7.2)$ & & & $17(8.7)$ & $14(7.2)$ & & \\
\hline Emergency & $7(3.2)$ & $10(3.7)$ & & & $5(2.6)$ & $6(3.1)$ & & \\
\hline \multicolumn{9}{|l|}{ Type of surgery } \\
\hline CABG & $113(52.2)$ & $151(56.7)$ & 0.382 & 11.4 & $105(54.1)$ & $114(58.7)$ & 0.676 & -0.8 \\
\hline Valve surgery & $98(45.3)$ & $112(42.1)$ & & & $86(44.3)$ & $77(39.7)$ & & \\
\hline Combined CV & $5(2.5)$ & $3(1.1)$ & & & $3(1.6)$ & $3(1.6)$ & & \\
\hline \multicolumn{9}{|l|}{ Internal thoracic artery } \\
\hline Harvested No & $84(38.9)$ & $111(41.7)$ & 0.187 & -10.2 & $73(37.6)$ & 76 (39.2) & 0.280 & -9.8 \\
\hline Harvested left only & $106(49.1)$ & $111(41.7)$ & & & $98(50.5)$ & $87(44.9)$ & & \\
\hline Harvested both & $26(12.0)$ & $44(16.6)$ & & & $23(11.9)$ & $31(15.9)$ & & \\
\hline \multicolumn{9}{|l|}{ Duration of operation } \\
\hline$<4 h$ & $51(23.6)$ & $46(17.3)$ & 0.078 & -12.8 & $45(23.2)$ & $46(23.7)$ & 0.775 & 0.9 \\
\hline$\geq 4 h$ & $165(76.4)$ & $220(82.7)$ & & & $149(76.8)$ & $148(76.2)$ & & \\
\hline
\end{tabular}

Values are presented as the number (\%) and mean \pm standard deviation. SD $=$ standardized differences as a percentage

$B M I$ body mass index, LV left ventricle, EF ejection fraction, EuroSCORE European System for Cardiac Operative Risk Evaluation, CABG coronary artery bypass graft, CV combined coronary and valve operation

This study was conducted to identify the use of prophylactic antibiotics and the source of infections and provide basic data for establishing antibiotic use guidelines. In a previous study, no differences were found in SSI rates after cardiac surgery between the third-generation and first-generation antibiotic groups, although a differences 
Table 2 Clinical outcomes of patients receiving 1st generation prophylactic antibiotics compared to 3rd generation

\begin{tabular}{lllll}
\hline & $\begin{array}{l}\text { 3rd generation } \\
(\mathbf{n}=\mathbf{1 9 4})\end{array}$ & $\begin{array}{l}\text { 1 st generation } \\
(\mathbf{n}=\mathbf{1 9 4})\end{array}$ & Crude OR (95\% Cl) & Adjusted OR (95\% Cl) \\
\hline All surgical site infections & $52(26.8)$ & $30(15.4)$ & $1.19(1.01-1.71)$ & $1.10(1.01-1.62)^{*}$ \\
Superficial surgical site infection & $20(10.3)$ & $19(9.8)$ & $0.91(0.71-1.30)$ & $0.87(0.62-1.11)$ \\
Deep SSI/mediastinitis & $32(16.5)$ & $11(5.7)$ & $1.36(1.11-2.08)$ & $1.25(1.07-1.91)^{* *}$ \\
\hline
\end{tabular}

Values are presented as the number (\%). ${ }^{*} p<0.05,{ }^{* *} p<0.001$

Adjustment variables: age, sex, DM, obesity, smoking, emergency, internal thoracic artery (ITA) harvested, ventilator time, duration of ICU stay, and enrollment period

Table 3 Comparison of ICU stay and hospitalization duration in the 1st and 3rd generation groups

\begin{tabular}{|c|c|c|c|c|c|}
\hline \multirow{2}{*}{$\begin{array}{l}\text { Duration } \\
\text { Hospitalization duration (d) }\end{array}$} & \multicolumn{2}{|c|}{ 3rd generation $(n=194)$} & \multicolumn{2}{|c|}{ 1st generation $(n=194)$} & \multirow{2}{*}{$\begin{array}{l}p \text { value } \\
0.025\end{array}$} \\
\hline & $29.8 \pm 18.7$ & & $25.5 \pm 20$ & & \\
\hline Preoperative hospitalization (d) & $8.4 \pm 8.6$ & & $7.8 \pm 7.6$ & & 0.262 \\
\hline Ventilation use time $(\mathrm{d})$ & $1.2 \pm 2.2$ & & $1.2 \pm 2.1$ & & 0.679 \\
\hline ICU stay $(\mathrm{d})$ & $4.1 \pm 3.8$ & & $2.9 \pm 2.7$ & & 0.008 \\
\hline SSI patients ICU stay (d) & $n=52$ & $8.9 \pm 4.8$ & $n=30$ & $7.1 \pm 4.7$ & 0.027 \\
\hline Non-infected patients ICU stay (d) & $n=142$ & $2.6 \pm 1.2$ & $n=164$ & $2.3 \pm 2.0$ & 0.088 \\
\hline
\end{tabular}

Values are presented as the mean \pm standard deviation. $p$ values were calculated using the Student's t-test

ICU intensive care unit, $d$ day

Table 4 Comparison of medical-cost expenditures (USD) in the 1st and 3rd generation groups

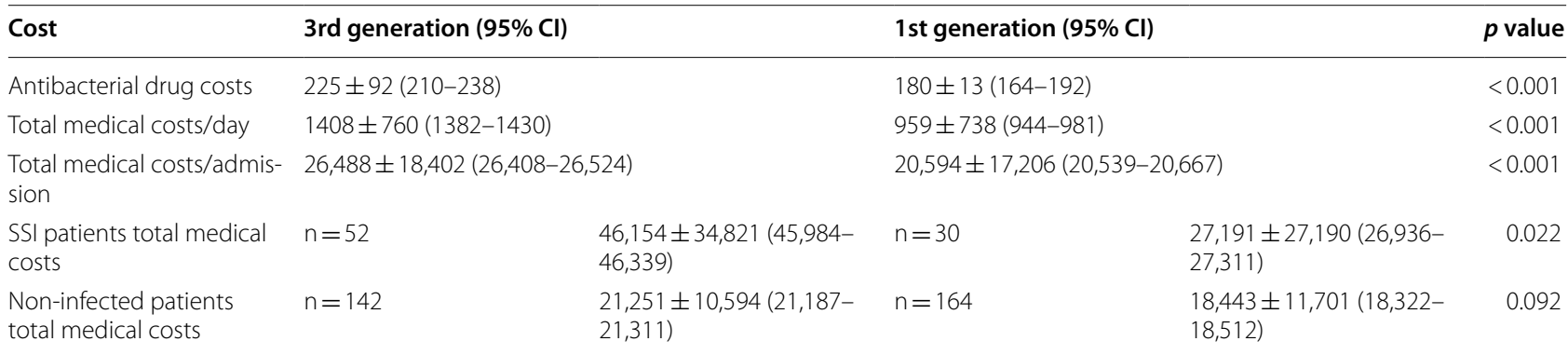

Values are presented as mean \pm standard deviation ( $95 \%$ confidence interval). $p$ values were calculated using the Student's t-test

ICU intensive care unit, $d$ day

were found between different antibiotic dosage and usage $[16,17]$. However, in this study, while no differences in superficial SSI rates were observed between the third- and first-generation groups, significantly lower SSI and deep SSI/mediastinitis rates were found in the first-generation group. Superficial SSIs may be caused by impaired cutaneous circulation, whereas deep SSIs may reflect the relationship between tissue perfusion and infection, including muscle, bone, and the mediastinum in the surgical site and are less frequent than superficial SSIs but have a shorter duration to diagnosis and higher mortality and morbidity. Deep SSIs are one of the most destructive cardiac surgery complications in patients and are different than superficial SSIs. Because the potential infection associations are substantially different, different treatment methods and strategies should be established. Therefore, the high incidence of deep SSIs in the thirdgeneration group was confounded by complex complications and surgical treatment, which lead to longer ICU stays and re-admission rates and doubles the risk of mortality [18]. The effect of SSIs is influenced by antibiotic resistance and the number of infections [19]. Gram-positive bacteria and gram-negative bacteria were cultured from the SSIs of $67 \%$ and $23 \%$ of the patients in the thirdgeneration group and from 62 and $24 \%$ of the patients in the first-generation group, respectively. $S$ aureus and coagulase-negative Staphylococci, known to be important pathogens responsible for SSIs in heart surgery, are frequently resistant to $\beta$-lactam antibiotics $[20,21]$. We found that the patients who received third-generation 
antibiotics for prophylaxis became significantly more colonized with methicillin-resistant coagulase-negative bacteria and $S$ aureus than the first-generation group. We observed a trend toward more SSIs in the patients who received third-generation antibiotic prophylaxis. Thus, SSIs caused by methicillin-resistant gram-positive cocci were more common among patients who received thirdgeneration antibiotics.

Considering that the antimicrobial characteristics of the two antibiotics differ, it is appropriate to use first-generation antibiotics because they have excellent antimicrobial activity against gram-positive bacteria and maintain a narrow range of antimicrobial activity. In addition, first-generation antibiotics are more effective in reducing medical costs and increasing safety because they have been used for a long time and are inexpensive. Bratzler et al. $[18,22]$ warned that the use of prophylactic antibiotics that are incompatible with guidelines is not only less effective in reducing SSIs, but the use of antibiotics over excessively broad antimicrobial ranges may increase the tolerance of other organisms. Barie et al. [23] reported that the choice of the appropriate prophylactic antibiotic is important to cover the range of surgical wound infection organisms and the use of inappropriate prophylactic antibiotics is not effective in reducing surgical wound infection rates. According to Bratzler et al. [18] prophylactic antibiotic selection recommends the use of narrow antibiotic ranges and older-used antibiotics due to factors such as cost, half-life, safety, and antibiotic resistance. Therefore, newer and broader range antibiotics should be avoided as they may increase tolerance. This study did not show any clear advantage of newer and broader range third-generation antibiotics in reducing SSI rates and methicillin-resistant infections in cardiac surgery. In addition, the preoperative conditions, surgical procedures and technique, and antibiotic administration were similar in both groups but differed significantly in their effectiveness to prevent infection. Considering the stability, resistance, and efficacy of the antibiotics, firstgeneration antibiotics are suitable prophylactic drugs for heart surgery.

The duration of hospital stays in the first-generation group was significantly shorter than in the thirdgeneration group. The preoperative hospital length of stay, operating time, and duration of ventilator use did not differ between the two groups. However, in the first-generation group, the ICU stay and hospitalization duration were both significantly shorter than in the third-generation group. In addition, in a comparison of the length of ICU stay between the SSI groups $(n=82)$ and the non-infected group $(n=306)$, the mean duration of ventilator use was $2.5 \pm 3.7$ days versus $0.99 \pm 1.4$ days $(p<0.001)$ and the mean ICU stay duration was $7.3 \pm 4.8$ days versus $2.4 \pm 1.4$ days $(p<0.001)$, respectively, significantly higher in the infected groups. This result may reflect the increased susceptibility to SSIs with the long-term use of ventilators and increased ICU stay duration, leading to increased treatment due to infection. Lola et al. [24] reported that patients using ventilators for more than $48 \mathrm{~h}$ in the ICU had five-fold higher SSI rates and were eight-fold more likely to be readmitted to the ICU due to complications. Therefore, the significant difference in the hospitalization duration between the two groups suggests that long-term ventilator use and ICU stay duration were independent risk factors for SSIs.

Prophylactic antibiotic prices vary slightly from manufacturer to manufacturer, but the first-generation is the oldest drug in the classification of cephalosporins and has the lowest cost. The costs of prophylactic antibiotics may be reflected in the overall cost of patient care and treatment. The total medical care expenditure was about 5800 USD higher in the third-generation group, excluding pre-surgery examination fees, cardiac surgery costs, and material costs for the treatment. In particular, while no difference was observed in total medical expenditures between patients in the non-infected group, a significant difference was found in the patients with SSIs. Third-generation antibiotic prophylaxis affected the length of hospitalization and increased the cost of medical care. This was reflected in increases in the SSI rate, hospitalization duration, and medical expenditures for additional treatments [25]. In addition, if the indirect costs that were not evaluated in this study, were added, SSI could result in significant economic losses.

This study had several limitations as a prophylactic antibiotic study. First, the SSI rate was higher than that of a previous study [17]. The patients were followed up within 30 days of surgery, and SSIs were judged according to the findings of the clinical physician, rather than the infection specialist physician. As such, the clinical physician might have overestimated the incidence of wound infections. Second, while all patients underwent the same surgical procedure, the enrollment period was eight years. Due to the long-term study of eight years, it was analyzed to see if there is a confounding factor by year. The period from 2014 to 2016 taken as a reference year, had the lowest number of infections, so it was analyzed over two years (see Additional file 2). Third, the numbers of enrolled patients with long-term SSIs were insufficient. Further studies are needed to identify additional interrelated risk factors, including variables that can affect SSIs. The prophylactic antibiotic treatment duration and incidence of SSIs need to be established through randomized clinical trials. 


\section{Conclusions}

The results of this study showed that the use of thirdgeneration prophylactic antibiotics increased the surgical site infection rate and the length of hospital stay compared to the use of first-generation antibiotics. In addition, the microbial cultures showed that the numbers of gram-positive bacteria and antibiotic resistant organisms at the surgical site were high. It is, therefore, important to select suitable prophylactic antibiotics. The selection of first-generation prophylactic antibiotics, with their long-term safety and low cost, was effective in reducing the rate of surgical site infections and decreasing hospitalization and medical expenditures.

\begin{abstract}
Abbreviations
CABG: Coronary artery bypass graft; CPB: Cardiopulmonary Bypass; Cl: Confidence interval; ECMO: Extracorporeal Membrane Oxygenation; EuroSCORE: European System for Cardiac Operative Risk Evaluation; HIRA: Health Insurance Review and Assessment Service; ITA: Internal thoracic artery; OR: Odds ratio; PSM: Propensity Score Matching; SSI: Surgical Site infection.
\end{abstract}

\section{Supplementary Information}

The online version contains supplementary material available at https://doi. org/10.1186/s13019-022-01763-4.

Additional file 1: Table S1. Microorganisms isolated according to surgical site infections and prophylactic antibiotics.

Additional file 2: Table S2. Clinical outcomes of surgical site infections in two-year intervals.

\section{Acknowledgements}

The author is grateful to Dr. Kim I for her kind guidance and encouragement The authors are grateful to the clinical medical institution members, nurses, and physicians to perform this study.

\section{Authors' contributions}

BSJ and KI: conceptualization; BSJ and Kl: formal analysis; KI and SJ: methodology; CES: data curation; BSJ and CES: investigation; and BSJ and Kl: writingoriginal draft. All authors read and approved the final manuscript.

\section{Funding}

Not applicable.

\section{Availability of data and materials}

The datasets of the current study are available from the corresponding author upon reasonable request.

\section{Declarations}

\section{Ethics approval and consent to participate}

The present study protocol was reviewed and approved by the Institutional Review Board of Inje University Sanggye Paik Hospital (Approval No. 2017-05011-003). Informed consent was obtained from all patients before enrollment.

\section{Consent for publication}

Not applicable.

\section{Competing interests}

The authors declare that they have no competing interests.

\section{Author details}

${ }^{1}$ Department of Health Science, Hanyang University Graduate School, Seoul, Korea. ${ }^{2}$ Department of Cardiovascular Surgery, Sanggye Paik Hospital, Inje University College of Medicine, Seoul, Korea. ${ }^{3}$ Department of Occupational and Environment Medicine, Hanyang University College of Medicine, Seoul, Korea.

Received: 22 June 2021 Accepted: 27 January 2022

Published online: 05 February 2022

\section{References}

1. Goodman JS, Schaffner W, Collins HA, Battersby EJ, Koenig MG. Infection after cardiovascular surgery — clinical study including examination of antimicrobial prophylaxis. N Engl J Med. 1968;278(3):117-23. https://doi. org/10.1056/NEJM196801182780301.

2. Fong IW, Baker CB, McKee DC. The value of prophylactic antibiotics in aorat-coronary bypass operations: a double-blind randomized trial. J Thorac Cardiovasc Surg. 1979;78(6):908-13. https://doi.org/10.1016/ S0022-5223(19)38034-1.

3. Kreter B, Woods M. Antibiotic prophylaxis for cardiothoracic operations: meta-analysis of thirty years of clinical trials. J Thorac Cardiovasc Surg. 1992;104(3):590-9. https://doi.org/10.1016/S0022-5223(19)34723-3.

4. Emori TG, Gaynes RP. An overview of nosocomial infections, including the role of the microbiology laboratory. Clin Microbiol Rev. 1993;6(4):428-42. https://doi.org/10.1128/cmr.6.4.428.

5. Kirkland KB, Briggs JP, Trivette SL, Wilkinson WE, Sexton DJ. The impact of surgical-site infections in the 1990s: attributable mortality, excess length of hospitalization, and extra costs. Infect Control Hosp Epidemiol. 1999;20(11):725-30. https://doi.org/10.1086/501572.

6. Park ES, Kim KS, Lee WJ, Jang SY, Choi JY, Kim JM. The economical impacts of surgical site infections. Korean J Nosocomial Infect Control. 2005;10(2):57-64.

7. Park CS, Kim KH, Chang JH, Choi BR, Lee BR, Lee JS, et al. Development of quality indicator about prophylactic antibiotics for preventing surgical infection. Health Insurance Review and Assessment Service, Contract No. 2009-E00582-00. 2009. https://url.kr/lciCVT. Accessed 13 July 2020.

8. Sakong P, Lee JS, Lee EJ, Ko KP, Kim CH, Kim Y, et al. Association between the pattern of prophylactic antibiotic use and surgical site infection rate for major surgeries in Korea. J Prev Med Public Health. 2009;42(1):12-20. https://doi.org/10.3961/jpmph.2009.42.1.12.

9. Kim KH, Park CS, Chang JH, Kim NS, Lee JS, Choi BR, et al. Association between prophylactic antibiotic use and surgical site infection based on quality assessment data in Korea. J Prev Med Public Health. 2010;43(3):235-44. https://doi.org/10.3961/jpmph.2010.43.3.235.

10. Engelman R, Shahian D, Shemin R, Guy TS, Bratzler D, Edwards F, et al. The Society of thoracic surgeons practice guideline series: Antibiotic prophylaxis in cardiac surgery, part II: antibiotic choice. Ann Thorac Surg. 2007;83(4):1569-76. https://doi.org/10.1016/j.athoracsur.2006.09.046.

11. Mangram AJ, Horan TC, Pearson ML, Silver LC, Jarvis WR. Guideline for prevention of surgical site infection, 1999: Hospital Infection Control Practices Advisory Committee. Infect Control Hosp Epidemiol. 1999;20(4):247-80. https://doi.org/10.1086/501620.

12. Garner JS, Jarvis WR, Emori TG, Horan TC, Hughes JM. CDC definitions of nosocomial infections. In: Olmsted RN, editor. APIC Infection control and applied epidemiology: principles and practice. Mosby Year Book Inc; 1996. p. 1-20.

13. Abu-Omar Y, Kocher GJ, Bosco P, Barbero C, Waller D, Gudbjartsson T, et al. European Association for Cardio-Thoracic Surgery expert consensus statement on the prevention and management of mediastinitis. Eur J Cardiothorac Surg. 2017;51(1):10-29. https://doi.org/10.1093/ejcts/ ezw326.

14. Lee W-S. Propensity score matching and variations on the balancing test. Empir Econ. 2011;44(1):47-80. https://doi.org/10.1007/ s00181-011-0481-0.

15. Bryan CS, Yarbrough WM. Preventing deep wound infection after CABG Tex Heart Inst J. 2013;40(2):125-39.

16. Jones RN, Wojeski W, Bakke J, Porter C, Searles M. Antibiotic prophylaxis of 1,036 patients undergoing elective surgical procedures: a prospective, randomized comparative trial of cefazolin, cefoxitin, and cefotaxime in a 
prepaid medical practice. Am J Surg. 1987;153(4):341-6. https://doi.org/ 10.1016/0002-9610(87)90573-3.

17. Beam TR, Raab TA, Spooner JA, Balderman SC, Aldridge J, Bahyana JN. Comparison of ceftriaxone and cefazolin prophylaxis against infection in open heart surgery. Am J Surg. 1984;148(4a):8-14.

18. Bratzler DW, Houck PM. Antimicrobial prophylaxis for surgery: an advisory statement from the National Surgical Infection Prevention Project. Am J Surg. 2005;189(4):395-404. https://doi.org/10.1016/j.amjsurg.2005.01.015.

19. Hassan M, Smith JM, Engel AM. Predictors and outcomes of sternal wound complications in patients after coronary artery bypass graft surgery. Am Surg. 2006;72(6):515-20. https://doi.org/10.1177/0003134806 07200611.

20. Tegnell A, Arén C, Öhman L. Coagulase-negative staphylococci and sternal infections after cardiac operation. Ann Thorac Surg. 2000;69(4):11049. https://doi.org/10.1016/S0003-4975(99)01563-5.

21. Söderquist B. Surgical site infections in cardiac surgery: microbiology. Acta Pathol Microbiol Immunol Scand. 2007;115(9):1008-11. https://doi. org/10.1111/j.1600-0463.2007.00833.x.

22. Bratzler DW, Houck PM. Antimicrobial prophylaxis for surgery: an advisory statement from the National Surgical Infection Prevention Project. Clin Infec Dis. 2004;38(12):1706-15. https://doi.org/10.1086/421095.

23. Barie PS, Eachempati SR. Surgical site infections. Surg Clin N Am 2005;85(6):1115-35. https://doi.org/10.1016/j.suc.2005.09.006.

24. Lola I, Levidiotou S, Petrou A, Arnaoutoglou H, Apostolakis E, Papadopoulos GS. Are there independent predisposing factors for postoperative infections following open heart surgery? J Cardiothorac Surg. 2011;6(1):151. https://doi.org/10.1186/1749-8090-6-151.

25. Ahn Y-J, Sohng K-Y. Factors related to surgical site infections in patients undergoing general surgery 2005. J Korean Acad Fundam Nurs. 2005;12(1):113.

\section{Publisher's Note}

Springer Nature remains neutral with regard to jurisdictional claims in published maps and institutional affiliations.

- fast, convenient online submission

- thorough peer review by experienced researchers in your field

- rapid publication on acceptance

- support for research data, including large and complex data types

- gold Open Access which fosters wider collaboration and increased citations

- maximum visibility for your research: over $100 \mathrm{M}$ website views per year

At BMC, research is always in progress.

Learn more biomedcentral.com/submissions 